\title{
A Novel Avian Paramyxovirus (Putative Serotype 15) Isolated from Wild Birds
}

\author{
Hyun-Jeong Lee ${ }^{1}$, Ji-Ye Kim ${ }^{2}$, Youn-Jeong Lee ${ }^{1}$, Eun-Kyung Lee ${ }^{1}$, Byoung-Min Song ${ }^{1}$, \\ Hee-Soo Lee ${ }^{1}$ and Kang-Seuk Choi ${ }^{1 *}$
}

${ }^{1}$ Avian Disease Division, Animal and Plant Quarantine Agency, Gimcheon-si, South Korea, ${ }^{2}$ Animal Veterinary Drugs and Biologics Division, Animal and Plant Quarantine Agency, Gimcheon-si, South Korea

In January 2014, a viral hemagglutinating agent named UPO216 was isolated from fecal droppings of wild birds at the UPO wetland in South Korea during an avian influenza surveillance program. Electron microscopy identified the UPO216 virus as an avian paramyxovirus (APMV). Pathogenicity tests and molecular pathotyping revealed that the virus was avirulent in chickens. The UPO216 virus was assigned to a serological group antigenically distinct from known serotypes of APMV $(-1,-2,-3,-4,-6,-7$, -8 , and -9 ) by hemagglutination inhibition test, despite showing weak cross-reactivity with APMV-1 and APMV-9. The UPO216 virus RNA genome is 15,180 nucleotides (nts) in length, encodes $3^{\prime}-\mathrm{N}-\mathrm{P}(\mathrm{V} / \mathrm{W})-\mathrm{M}-\mathrm{F}-\mathrm{HN}-\mathrm{L}-5^{\prime}$ in that order, and shows unique genetic characteristics in terms of genomic composition and evolutionary divergence $(0.43$ or greater from known serotypes of APMV). Phylogenetic analysis revealed that the UPO216 occupies a branch separate from APMV-1, -9, -12, and -13. Serologic surveillance of wild birds ( $n=880 ; 15$ species, five Orders) detected UPO216-reactive antibodies in 4\% (20/494) of serum samples taken from five species of wild duck belonging to the Order Anseriformes. In particular, UPO216-specific antibodies showing no cross-reaction with other serotypes of APMV were detected in four species: Eurasian teal (1/36), European wigeon (1/73), mallard (4/139), and Spot-Billed duck (1/137). These results indicate that the UPO216 virus has antigenically and genetically unique characteristics distinct from known serotypes of APMV and likely has been circulating widely in wild duck species of the Order Anseriformes. Thus, we propose the UPO216 isolate as a prototype strain of a novel APMV serotype (putative APMV-15).

Keywords: avian paramyxovirus, wild duck, UPO wetland, novel serotype, serotype 15

\section{INTRODUCTION}

Avian paramyxoviruses (APMVs) belong to the genus Abulavirus within the family Paramyxoviridae. The genomes of APMVs contain a non-segmented negative sense singlestranded RNA ranging from 15 to $17 \mathrm{~kb}$ in length and encoding at least six proteins, nucleocapsid $(\mathrm{N})$, phospho- $(\mathrm{P})$, matrix $(\mathrm{M})$, fusion $(\mathrm{F})$, hemagglutinin-neuraminidase $(\mathrm{HN})$, and a large polymerase (L). Two additional proteins, $\mathrm{V}$ and $\mathrm{W}$, may be produced by an RNA editing event during transcription of the P gene (Miller et al., 2010a; Samuel et al., 2010; Samal, 2011). APMV serotype 6 (APMV-6) contains a small hydrophobic protein $(\mathrm{SH})$ gene between the F and HN genes, which is not found in other APMV serotypes (Chang et al., 2001; Samuel et al., 2010). 
APMVs are divided into 14 different serotypes (APMV-1 to -14 ) according to cross-hemagglutination inhibition (HI) testing (Alexander, 2003) and/or by phylogenetic analysis (Miller et al., 2010a; Terregino et al., 2013; Yamamoto et al., 2015; Thampaisarn et al., 2017). To date, numerous APMVs have been isolated from domestic and wild birds worldwide. Nine known serotypes (APMV-1 to -9) were discovered worldwide before the 1980s, and some APMV serotypes infect domestic poultry. Poultry, especially chickens, are highly susceptible to APMV1, also known as Newcastle disease virus (NDV), which causes substantial economic losses; however, serotypes APMV-2, -3, -6 , and -7 cause only mild respiratory illness and/or egg drop in chickens and turkeys (Suarez et al., 2013).

Since 2005, more than four novel APMV serotypes (APMV -10 to -14 ) have been isolated from wild bird populations. APMV serotypes $-10,-11$, and -12 were isolated from Rockhopper penguins (Eudyptes chrysocome) in the Falkland Islands in 2007 (Miller et al., 2010a), common snipes (Gallinago gallinago) in France in 2010 (Briand et al., 2012), and Eurasian wigeon (Anas penelope) in Italy in 2005 (Terregino et al., 2013), respectively. Recently, novel APMVs (putative APMV-13 and 14) were isolated from wild birds around the world during an of avian influenza (AI) surveillance program; species included wild migratory geese in Japan in 2010 (Yamamoto et al., 2015), a white-fronted goose in Ukraine in 2011 (Goraichuk et al., 2016), a white-fronted goose in Kazakhstan in 2013 (Karamendin et al., 2016), and wild ducks in Japan in 2011 (Thampaisarn et al., 2017).

The emergence and worldwide spread of the H5N1 highly pathogenic avian influenza virus (AIV) in poultry and wild birds in the early 2000s spurred the development of AI surveillance programs to better understand the ecology of AIVs in wild birds, especially waterfowl, worldwide (Miller et al., 2010a). This has provided opportunities to better understand the ecology of APMVs, for which wild birds are considered natural hosts (Samal, 2011; Suarez et al., 2013).

Since 2003, Korea has conducted a surveillance program aimed at better understanding the ecology of AIVs in wild birds, live poultry markets, and poultry farms. As part of this program, a non-AIV viral hemagglutinating agent was isolated from wild migratory ducks (species unknown) in the southern region of South Korea in January 2014. Here, we examined the biological properties and genomic features of this isolate to determine whether the virus is a novel APMV.

\section{MATERIALS AND METHODS}

\section{Virus Isolation}

A hemagglutinating agent, UPO216, was isolated from fresh wild bird droppings collected at the UPO wetlands $\left(35^{\circ} 33^{\prime} 13.9^{\prime \prime} \mathrm{N}\right.$ $\left.128^{\circ} 24^{\prime} 50.0^{\prime \prime} \mathrm{E}\right)$ in the Gyeongnam province of Korea during an AI surveillance program in 2014 by inoculation into the allantoic cavities of 9-11-day-old specific pathogen-free (SPF) embryonated chicken eggs (ECEs, Valo BioMedia, USA) as previously described (Kang et al., 2010). The isolate was propagated in ECEs and UPO216 was named after the geological location of virus isolation. HA-positive allantoic fluids tested negative for AIV and APMV-1 by reverse-transcription polymerase chain reaction (RT-PCR) (Choi et al., 2012; Lee et al., 2014). The virus titer was measured by end-point titration in ECEs and expressed as the $50 \%$ egg infective dose $\left(\mathrm{EID}_{50}\right)$, as calculated by the Reed and Muench method (Reed and Muench, 1938).

\section{Electron Microscopy}

For electron microscopy, UPO216 virus contained in allantoic fluid was concentrated by $20-60 \%(w / v)$ continuous sucrose gradient centrifugation at $90,000 \times \mathrm{g}$ for $1.5 \mathrm{~h}$ at $4^{\circ} \mathrm{C}$ in a Beckman SW41 rotor (Beckman, Germany). Each fraction was collected and tested for HA activity. HA-positive fractions were diluted in phosphate buffered saline (PBS, $\mathrm{pH} 7.4$ ) and precipitated by centrifugation at 26,000 $\times \mathrm{g}$ for $6 \mathrm{~h}$ at $4^{\circ} \mathrm{C}$. The pellet was resuspended in PBS and kept at $4^{\circ} \mathrm{C}$ until use. Purified virus was adsorbed to 300 mesh copper grids at room temperature. The grids were negatively stained with $2 \%$ uranyl acetate and examined under a Hitachi 7100 electron microscope (Hitachi, Japan) at a magnification of $\times 100,000$.

\section{Virus Serotyping}

To serotype APMVs, a cross-HI test was performed using a reference panel comprising antigens and chicken anti-sera against representatives of APMV-1 to APMV-9 (except APMV5; National Veterinary Service Laboratories, USA) using the method outlined in OIE (world organization for animal health) terrestrial manuals (OIE, 2012). Chicken antiserum homologous for the UPO216 virus was prepared by intravenously injecting 3week-old SPF chickens with purified UPO216 virus (10 ${ }^{9.0}$ EID $_{50}$ per dose) as previously described (Miller et al., 2010a). The antigenic relatedness $(\mathrm{R})$ between the two viruses was calculated using the method of Archetti and Horsfall (1951): $R=\left(r_{1} \times\right.$ $\left.r_{2}\right)^{1 / 2}$, where $r_{1}$ is the ratio of the heterologous HI titer to the homologous HI titer for virus 1 and $r_{2}$ is the ratio of the heterologous HI titer to the homologous HI titer for virus 2.

\section{In vivo Pathogenicity Testing}

The virulence of the virus was determined by the intracerebral pathogenicity index (ICPI) in day-old SPF chicks and the mean death time (MDT) in 9-11-day-old embryonated SPF ECEs, as previously described (Choi et al., 2012). All procedures were approved and supervised by the Institutional Animal Care \& Use Committee of the Animal and Plant Quarantine Agency (QIA).

\section{Genome Sequencing}

Viral RNA was extracted from the allantoic fluid using a QIAmp viral RNA mini kit (Qiagen, USA) according to the manufacturer's instructions. Complementary DNA synthesis was performed using a LaboPass ${ }^{\mathrm{TM}}$ cDNA synthesis kit (Cosmogenetech, Korea). A combination of $\mathrm{F}$ gene-specific primers and primer walking was used to generate PCR amplicons covering the genome (except for both ends). The sequences of the $3^{\prime}$ and $5^{\prime}$ ends of the genome were amplified using the rapid amplification of cDNA ends (RACE) method (Li et al., 2005). All primer sets are described in Table 1. All PCR amplicons were sequenced using fluorescent dideoxynucleotide terminators 
TABLE 1 | Primers used for sequencing of full-length genome of UPO216 virus in this study.

\begin{tabular}{|c|c|c|c|}
\hline Name & Sequences $\left(3^{\prime} \rightarrow 5^{\prime}\right)$ & Size (bp) & Usage \\
\hline $53 \mathrm{~F}$ & CGYACGGGTAGAAGGTGTGA & 20 & Sequensing \\
\hline $1561 \mathrm{~F}$ & AGGCAACCAAGACCAGGATCAGG & 23 & Sequensing \\
\hline $1814 \mathrm{R}$ & CTTCTACCCGTAYTIIITCTA & 22 & Sequensing \\
\hline $2223 \mathrm{~F}$ & ATACGGACAGGTGCGAGCTC & 20 & Sequensing \\
\hline $2921 F$ & AGTGAAGGCTAGTCAGGCGC & 20 & Sequensing \\
\hline $3257 \mathrm{~F}$ & TAAGAAAAAATACGGGTAGAAT & 22 & Sequensing \\
\hline $4138 \mathrm{R}$ & TGAAGGGCCGAGAACATC & 18 & Sequensing \\
\hline 4520R & CTTCTACCCGTGTITITCTAA & 22 & Sequensing \\
\hline $4541 \mathrm{~F}$ & TCTGСССТCСТTTGATAATCCAA & 23 & Sequensing \\
\hline $4885 \mathrm{~F}$ & GACCGAAACAGCAGGATTAGTTCAGG & 26 & Sequensing \\
\hline 4896R & GCTGTTCGGTCGTTGACTCGTGTAT & 26 & Sequensing \\
\hline $5274 \mathrm{R}$ & TGAATACTGAGTGGACTAAGAGCCGGA & 27 & Sequensing \\
\hline $5623 F$ & CTTCCCTATGTCTCCAGG & 18 & Sequensing \\
\hline $6116 \mathrm{~F}$ & TCTCCTGTGACAGGTAGTAG & 20 & Sequensing \\
\hline $6654 \mathrm{~F}$ & YCAAGATGTCRTAGATAGG & 19 & Sequensing \\
\hline $7668 \mathrm{R}$ & CTCCAATGTGCATGACTC & 18 & Sequensing \\
\hline $8210 \mathrm{~F}$ & TGATGCCATCGCAGAACCCC & 20 & Sequensing \\
\hline $8401 R$ & GCYYGCCATGTCCTACCCGT & 20 & Sequensing \\
\hline $8943 \mathrm{~F}$ & ACAGCTCCAGCGACATTT & 18 & Sequensing \\
\hline 9095F & TTGATGTATGCRGATATGAT & 20 & Sequensing \\
\hline 9773F & ACTTCGACCCAGTCTCAA & 18 & Sequensing \\
\hline 10524R & ACGATRTATATGTCATCATT & 20 & Sequensing \\
\hline $10578 \mathrm{~F}$ & GACAATGATTTCCATATCTG & 20 & Sequensing \\
\hline 12201R & TTCCTGCTGTTGGGAGCGGT & 20 & Sequensing \\
\hline $12932 R$ & GATATGGTTGCTGCTATG & 18 & Sequensing \\
\hline 13788R & GCGGCACATGCAACTCTA & 18 & Sequensing \\
\hline $14240 F$ & MGAGGRGATATGGAGTGTTA & 20 & Sequensing \\
\hline $14459 R$ & TAAGCCCTGGGGTGGGTAGA & 20 & Sequensing \\
\hline $15179 R$ & ACCAAACARAGATTTGGTGA & 20 & Sequensing \\
\hline 398R1 & GTCCAGCTAGGGCAACAT & 18 & $3^{\prime}$ RACE \\
\hline 303R2 & CTAACTGCCACTCTGAGG & 18 & 3'RACE \\
\hline 14325PF & phospho-AGGTGGTGAGGATGGCGAAG & 28 & 5'RACE \\
\hline $14862 \mathrm{~F} 1$ & GGAGCACCTGCCCAAAATA & 19 & 5'RACE \\
\hline 14652R1 & GCTAGTGCACCGCCTTCTT & 19 & 5'RACE \\
\hline 14979F2 & TTATCGGGAATGCAATCAAAG & 21 & 5'RACE \\
\hline 14618R2 & ATCTAATGGCAGTATCTATGTGG & 23 & 5'RACE \\
\hline
\end{tabular}

and an automated sequencer (ABI 3730XL automated sequencer; Applied Biosystems Inc., USA).

\section{Phylogenetic Analysis}

Genome sequences of representative viruses belonging to the family Paramyxoviridae and sequences of each APMV serotype (all available in GenBank) were used for phylogenetic comparison. Editing and sequence analyses were performed using the BioEdit sequence alignment editor (Hall, 1999). Alignment of multiple nt and amino acid (aa) sequence alignments for the complete genome, the $\mathrm{F}$ gene, and the $\mathrm{HN}$ gene was performed using CLC Genomic Workbench 6.7.2 (CLC bio Aarhus, Denmark). Phylogenetic analysis was performed in MEGA 7.0 (Kumar et al., 2016) using both the maximum parsimony and maximum likelihood methods, with 1,000 bootstrap replicates. The evolutionary distance between and within APMV serotypes was determined using MEGA 7.0 (over 1,000 bootstrap replicates; Kumar et al., 2016).

\section{Accession Numbers}

Genome sequences of representative APMV serotypes were retrieved from GenBank public databases and used for the alignments. The GenBank accession numbers are as follows: APMV-1, accession nos. JF950510, AJ88027, and JF893453; APMV-2, accession nos. HM159993, HM159995, and HQ896023; APMV-3, accession nos. EU403085 and EU782025; APMV-4, accession nos. FJ177514 and EU877976; APMV-5, accession no. GU206351; APMV-6, accession nos. JN571486 and GQ406232; APMV-7, accession no. FJ231524; APMV-8, accession no. FJ619036; APMV-9, accession no. EU910942; APMV-10, accession no. HM159995; APMV-11, accession no. JQ886184; APMV-12, accession no. KC333050; APMV13, accession nos. LC041132 and KX119151; and APMV-14, accession no. KX258200.

\section{Serological Surveillance}

A total of 880 serum samples from wild birds in Korea were examined. The serum samples were originally taken from wild birds captured for an AI surveillance program; samples were kept at the AI laboratory, QIA, Korea. The serum samples were obtained from five Orders: Anseriformes, Charadriiformes, Ciconiiformes, Columbiformes, and Passeriformes covering 15 species. Sera were heat-inactivated at $56^{\circ} \mathrm{C}$ for $30 \mathrm{~min}$ before use in the serologic assay. Serological HI tests employing four $\mathrm{HA}$ units of test antigen in V-bottom microtiter plates were performed as described previously (OIE, 2012). The serum samples were first screened for the UPO216 virus isolated in the present study, and positive samples were further tested for crossreaction with other APMV serotypes. The HI antibody titer was calculated as the reciprocal of the highest serum dilution that completely inhibited $4 \mathrm{HA}$ units of antigens. HI titers $\geq 8\left(3 \log _{2}\right)$ were considered positive. All tests were repeated twice.

\section{RESULTS}

\section{Biological Characterization}

The UPO216 virus was successfully propagated in ECEs, and the harvested infective allantoic fluid had a titer of $10^{9.3}$ $\mathrm{EID}_{50}$ per $\mathrm{ml}$ and a $\mathrm{HA}$ titer of 1,024-2,048 per $25 \mu \mathrm{l}$. Electron microscopy revealed that the UPO216 virus particles showed pleomorphic morphology, with a diameter of $80-$ $300 \mathrm{~nm}$. Glycoprotein projections of approximately $10 \mathrm{~nm}$ in length were evenly distributed across the envelope of the virus particle. Herringbone-like structures (nucleocapsids) were packaged inside the virion (Figure 1). These characteristics are typical of a paramyxovirus. In vivo pathogenicity testing revealed that UPO216 had a MDT index of $>120 \mathrm{~h}$ and an ICPI-value of 0.00 (Table 2), indicating that it is avirulent in chickens. Serotyping revealed that UPO216 had a high HI titer $(1: 1,024)$ for homologous chicken antiserum (as expected), but 
low cross-reactivity (HI titers of $\leq 1: 128$ ) with several APMV serotypes, including APMV-1 and -9. The R between UPO216 virus and APMV serotypes was then calculated based on the HI titers obtained from the cross-HI test (Table 3). The UPO216 virus showed an $R$-value of $<0.05$ for all APMV serotypes except APMV-1 $(R=0.088)$ and APMV-9 $(R=0.125)$. The higher

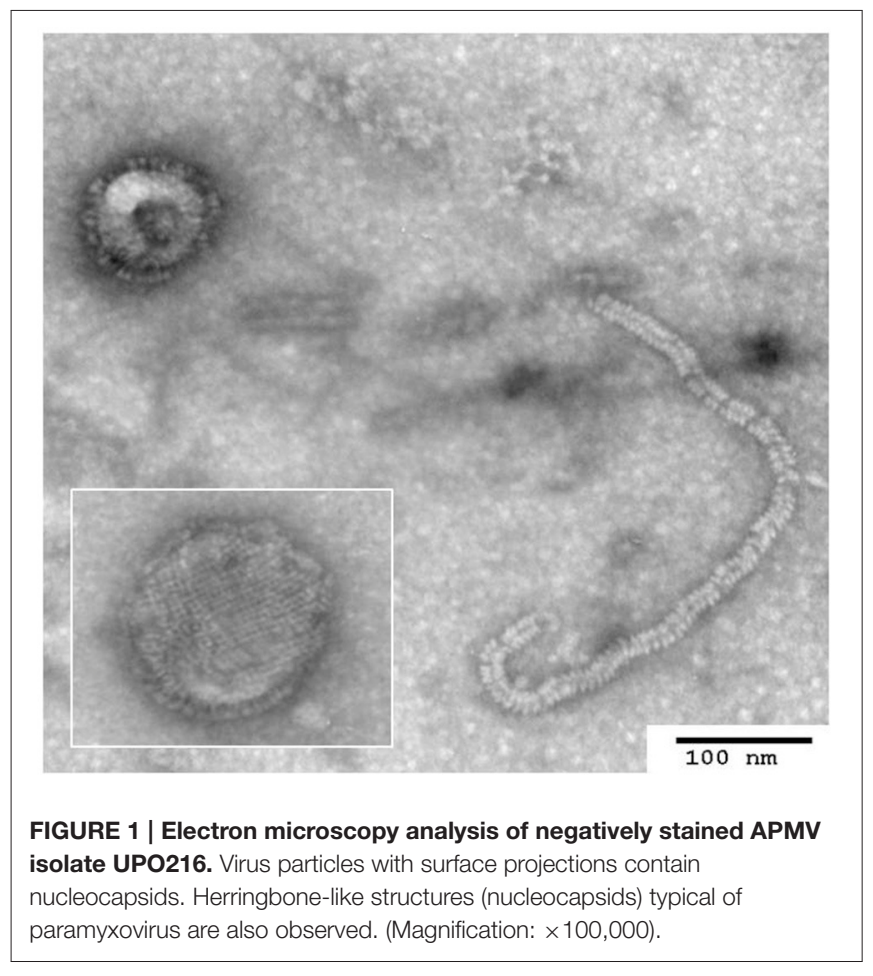

$R$-values for APMV-1 and APMV-9 were due to weak crossreactions in the cross-HI test.

\section{Complete Genome Sequence}

The nt sequence of the UPO216 virus was compiled from the sequences of 28 overlapping cDNA clones covering the entire genome. The UPO216 genome comprises 15,180 nts (accession no. KY511044). This length conforms to the "rule of six," which plays an important role in the replication of paramyxoviruses (Kolakofsky et al., 1998).

A genome-wide BLASTN search (http://blast.ncbi.nlm.nih.gov/Blast.cgi) showed that UPO216 was closely related with known APMVs, especially with the highest identity with NDV strain 08-004 (accession no FJ794269.1; 75\% identity) for $\mathrm{N}$ protein gene (positions 1-1,326) and with NDV strain BHG/Sweden/94 (accession no GQ918280; $72 \%$ identity) for $\mathrm{L}$ gene (positions 9,415-12,945). This indicates that the UPO216 virus might be an APMV.

The genome of UPO216 contains six non-overlapping transcriptional units in the following order: $3^{\prime}$-leader-NP-P-MF-HN-L-trailer-5' (Figure 2). Two additional proteins, V (245 aa) and $\mathrm{W}(140 \mathrm{aa})$, may arise during transcription of the $\mathrm{P}$ gene due to a putative RNA editing site (nt positions 2,292-2,300) in the viral genome. This occurs via addition of a single $G$ residue to the editing site to yield a predicted $\mathrm{V}$ protein and the addition of two $G$ residues to yield a predicted $W$ protein, as is the case for APMV-1 (Steward et al., 1993). However, SH gene, that is found in APMV-6 (Chang et al., 2001), is not present between the $\mathrm{F}$ and $\mathrm{HN}$ genes. The $3^{\prime}$ leader sequence is $55 \mathrm{nt}$ in length; this length is conserved among most APMV serotypes (Samuel et al., 2010; Samal, 2011). The length of the trailer at the $5^{\prime}$ end is $47 \mathrm{nt}$, the same as that in APMV-9 (Samuel et al., 2009; Figure 2). The first $12 \mathrm{nt}$ of the leader sequence (3'-UGGUUU GUCUCU-5')

TABLE 2 | Prototype APMVs and UPO/14 and their pathogenicity in chickens.

\begin{tabular}{|c|c|c|c|c|c|}
\hline APMVs & Isolate & $\mathrm{F}$ cleavage & MDT (h) & ICPI & References \\
\hline UPO216 & UPO216 & LVQAR $\downarrow L$ & $>120$ & 0.00 & This study \\
\hline \multirow[t]{2}{*}{ APMV-1 } & LaSota (avirulent) & GRQGR $\downarrow L$ & 112 & 0.00 & Kim et al., 2012 \\
\hline & BC (virulent) & $R R Q K R \downarrow F$ & 58 & 1.55 & Kim et al., 2012 \\
\hline \multirow[t]{2}{*}{ APMV-2 } & California/Yucaipa/56 & KPASR $\downarrow F$ & $>168$ & 0.00 & Subbiah et al., 2010 \\
\hline & Bangor/1973 & TLPSAR $\downarrow F$ & $>168$ & 0.00 & Subbiah et al., 2010 \\
\hline APMV-4 & Hong Kong/D3/1975 & $\mathrm{DIQPR} \downarrow \mathrm{F}$ & $>144$ & 0.00 & Kumar et al., 2010 \\
\hline APMV-5 & Kunitachi/1974 & $\mathrm{KRKKR} \downarrow \mathrm{F}$ & $>144$ & 0.00 & Kumar et al., 2010 \\
\hline APMV-6 & Hong Kong/199/1977 & APEPR $\downarrow$ L & $>144$ & 0.00 & Kumar et al., 2010 \\
\hline APMV-7 & TN/4/1975 & LPSSR $\downarrow F$ & $>144$ & 0.00 & Kumar et al., 2010 \\
\hline APMV-8 & DE/1053/1976 & YPQTR $\downarrow L$ & $>144$ & 0.00 & Kumar et al., 2010 \\
\hline APMV-12 & Italy/3920-1/2005 & GREPR $\downarrow L$ & NA & 0.45 & Terregino et al., 2013 \\
\hline APMV-13 & Shimane/67/2000 & VRENR $\downarrow L$ & $>120 \mathrm{~h}$ & 0.0 & Yamamoto et al., 2015 \\
\hline APMV-14 & Japan/11OG0352/2011 & TREGK $\downarrow$ L & NA & 0.0 & Thampaisarn et al., 2017 \\
\hline
\end{tabular}


TABLE 3 | Antigenic relatedness of avian paramyxoviruses as determined by Archetti and Horsfall calculations based on $\mathrm{HI}$ test results.

\begin{tabular}{|c|c|c|c|c|c|c|c|c|c|}
\hline \multirow[t]{2}{*}{ Virus } & \multicolumn{9}{|c|}{ Antiserum } \\
\hline & UPO216 & APMV-1 & APMV-2 & APMV-3 & APMV-4 & APMV-6 & APMV-7 & APMV-8 & APMV-9 \\
\hline UPO216 & 1.000 & $0.098^{a}$ & 0.008 & 0.044 & 0.016 & 0.003 & 0.044 & 0.031 & 0.125 \\
\hline APMV-2 & & & 1.000 & 0.011 & 0.008 & 0.022 & 0.031 & 0.008 & 0.004 \\
\hline APMV-3 & & & & 1.000 & 0.016 & 0.006 & 0.044 & 0.008 & 0.044 \\
\hline APMV-7 & & & & & & & 1.000 & 0.011 & 0.044 \\
\hline APMV-8 & & & & & & & & 1.000 & 0.011 \\
\hline APMV-9 & & & & & & & & & 1.000 \\
\hline
\end{tabular}

${ }^{a}$ Numbers represent R-values calculated from the cross-HI results using the method of Archetti and Horsfall (1951). Homologous viruses give values of 1.

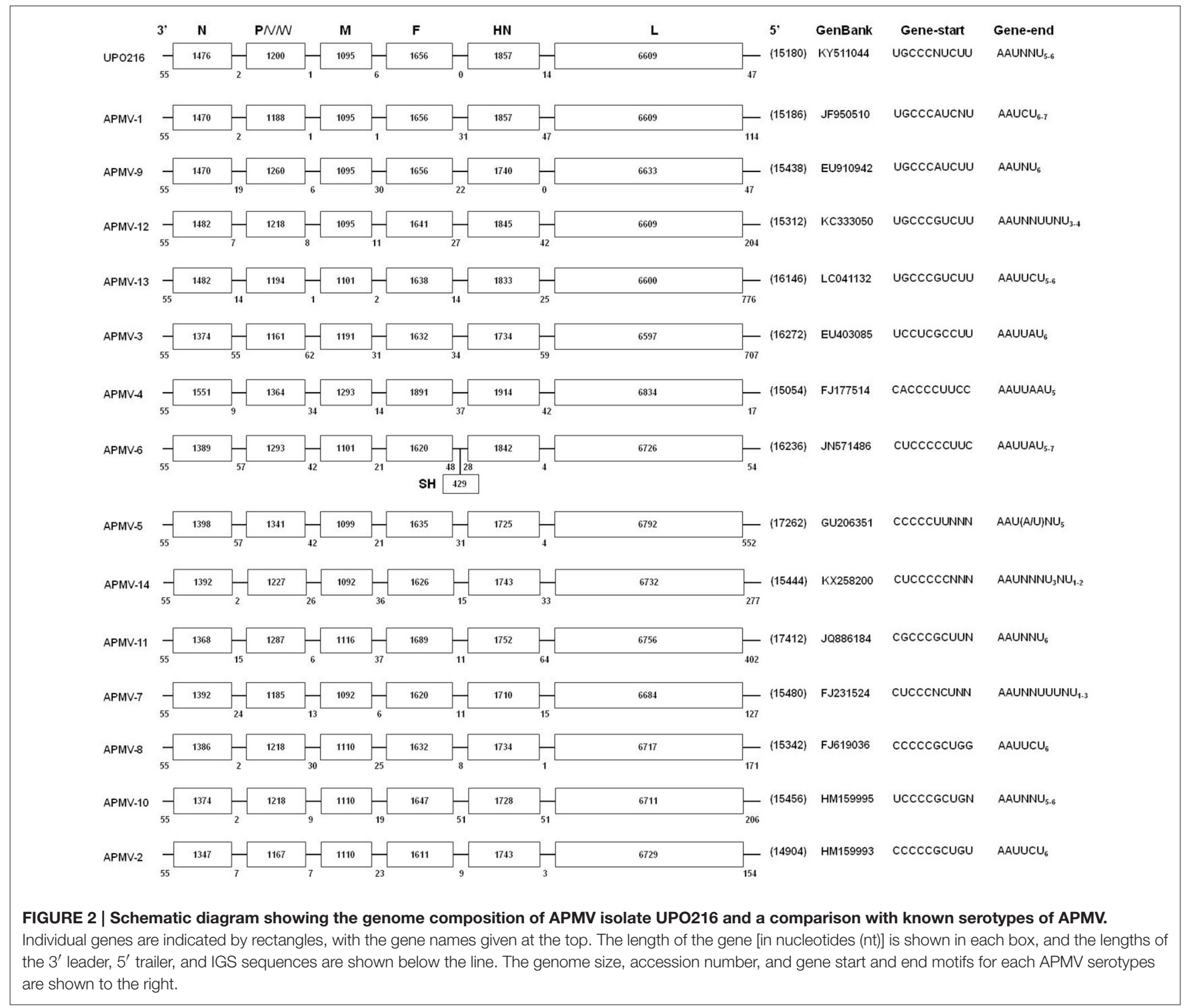


and the last eight nt of the $5^{\prime}$ trailer sequence $\left(5^{\prime}\right.$-ACCAAA CAAAGA-3') show a high degree of homology (91.7\%). The conserved sequences for the gene start (GS) and gene end (GE) of the UPO216 virus are $\mathrm{UGC}_{3} \mathrm{~A} / \mathrm{CUCUU}$ and $\mathrm{AAUNC/U_{5-6 }}$, respectively. The length of the intergenic region sequences ranges from 0 to $14 \mathrm{nt}$. The $\mathrm{F}$ protein cleavage sites within UPO216 possess the following unique aa sequence: ${ }^{110} \mathrm{~L}-\mathrm{V}-\mathrm{Q}-\mathrm{A}-\mathrm{R}-\mathrm{L}^{115}$ (Table 2).

Comparison of the complete consensus sequences for the UPO216 genome with those of known APMV serotypes revealed that UPO216 is most closely related to APMV-1 (64.0\% identity), followed by APMV-9 (56.4\%), APMV-12 (52.9\%), and APMV13 (50.9\%) (Table 4). UPO216 shows low homology with other APMV serotypes (37.0-41.1\%).

\section{Phylogenetic Analysis}

A phylogenetic tree was constructed based on alignment of the complete nt sequences of the UPO216 genome and F gene with those of representative APMV serotypes (Figure 3). Phylogenetic analysis based on the complete sequences revealed that UPO216 formed a separate phylogenetic group along with APMV-1, -9, -12 , and -13 (Figure 3A). Within this group, UPO216 is more closely related to APMV-1 and APMV-9 than to APMV-12 and APMV-13. APMV-3 viruses are closely related to APMV-4 viruses, APMV-5 viruses to APMV-6 and APMV-14 viruses, and APMV-8 to APMV-10 and APMV-2 viruses. Similar results were observed for phylogenetic analyses based on $\mathrm{F}$ gene sequences (Figure 3B).

\section{Evolutionary Relatedness}

To determine the genetic distance between the UPO216 and known APMV serotypes, we calculated the inter-serotype and intra-serotype evolutionary distances among APMV serotypes based on the sequences of complete genome (Table 5). At the genome level, estimates of the average inter-serotypic distance ranged from 0.43 to 1.62 . The lowest inter-serotypic distance was between APMV-1 and UPO216 (0.43), followed by APMV12 and APMV-13 (0.54), APMV-9 and UPO216 (0.64), APMV2 and -10(0.69), and APMV-8 and APMV-10(0.69). When evolutionary distance was calculated with known serotypes of APMV, UPO216 was relatively close to APMV-1(0.43), APMV9(0.64), APMV-12(0.78) and APMV-13(0.77), compared to other APMV serotypes (1.35-1.55). Estimates of intra-serotypic distances for APMV-1, $-2,-3$, and -6 were $0.21,0.21,0.30$, and 0.26 , respectively.

\section{Serological Surveillance of Wild Birds}

The 880 serum samples examined herein were first tested for antibodies specific for UPO216 in the HI test. Of these, 20 sera reacted with UPO216 (Table 6). These seropositive results were observed in sera obtained from wild ducks (Eurasian teal, European wigeon, mallard, Spot-Billed duck, and mandarin duck) belonging to the Order Anseriformes, but not in sera obtained from birds belonging to the Orders Charadriiformes, Ciconiiformes, Columbiformes, and Passeriformes. When seropositive sera $(n=20)$ were further tested in HI tests based on antigens derived from other serotypes of APMV, seven [Eurasian teal $(n=1)$, mallard $(n=4)$, European wigeon $(n=1)$, and Spot-Billed duck $(n=1)$ ] did not cross-react with other APMV serotypes tested, and HI titers for UPO216 ranged from $3 \log _{2}$ to $>6 \log _{2}$. The $\mathrm{HI}$ titers of the other 13 sera were the same (or higher) for APMV-1 as for UPO216.

\section{DISCUSSION}

Wild birds, especially waterfowl, are considered the natural reservoir for a variety of avian viruses (e.g., AIVs) with the potential to cause infectious diseases in poultry. In recent years, several novel APMVs belonging to APMV serotypes 10-14 were

TABLE 4 | Percentage nucleotide identity of complete genome sequences of APMVs representing groups APMV-1 to APMV-14.

\begin{tabular}{|c|c|c|c|c|c|c|c|c|c|c|c|c|c|c|c|}
\hline APMV serotype & 1 & 2 & 3 & 4 & 5 & 6 & 7 & 8 & 9 & 10 & 11 & 12 & 13 & 14 & UPO216 \\
\hline \multicolumn{16}{|l|}{1} \\
\hline 2 & 41.2 & & & & & & & & & & & & & & \\
\hline 3 & 36.6 & 36.2 & & & & & & & & & & & & & \\
\hline 4 & 38.0 & 37.5 & 44.3 & & & & & & & & & & & & \\
\hline 5 & 37.6 & 40.8 & 35.6 & 35.0 & & & & & & & & & & & \\
\hline 6 & 39.4 & 42.9 & 35.1 & 36.3 & 43.8 & & & & & & & & & & \\
\hline 7 & 41.1 & 47.2 & 36.6 & 37.9 & 41.9 & 43.3 & & & & & & & & & \\
\hline 8 & 40.9 & 55.5 & 36.3 & 37.6 & 41.2 & 43.2 & 48.6 & & & & & & & & \\
\hline 9 & 56.7 & 40.3 & 36.6 & 37.7 & 37.2 & 39 & 41.0 & 41.0 & & & & & & & \\
\hline 10 & 41.0 & 54.1 & 35.9 & 38 & 41.2 & 44.2 & 47 & 54.4 & 41.6 & & & & & & \\
\hline 11 & 37.1 & 41.2 & 36 & 34.8 & 51.2 & 40.2 & 42.3 & 41.7 & 37.4 & 42.1 & & & & & \\
\hline 12 & 53.5 & 40.2 & 36.3 & 37.9 & 37.4 & 38.7 & 40.9 & 40.6 & 52.5 & 40.7 & 37.5 & & & & \\
\hline 13 & 50.8 & 39 & 38.2 & 36.3 & 37.8 & 37.7 & 40.4 & 39.9 & 49.4 & 38.9 & 38.3 & 58.2 & & & \\
\hline 14 & 40.2 & 44.6 & 36.5 & 37.3 & 44.3 & 49.9 & 44.6 & 45.8 & 40.2 & 45.6 & 41.0 & 40.3 & 39.4 & & \\
\hline UPO216 & 64.0 & 40.8 & 36.2 & 37.9 & 37.0 & 38.5 & 41.1 & 41.0 & 56.4 & 40.8 & 37.5 & 52.9 & 50.9 & 40.4 & \\
\hline
\end{tabular}

The numbers of the closest identity (\%) between viruses of the two APMV groups are shown. 

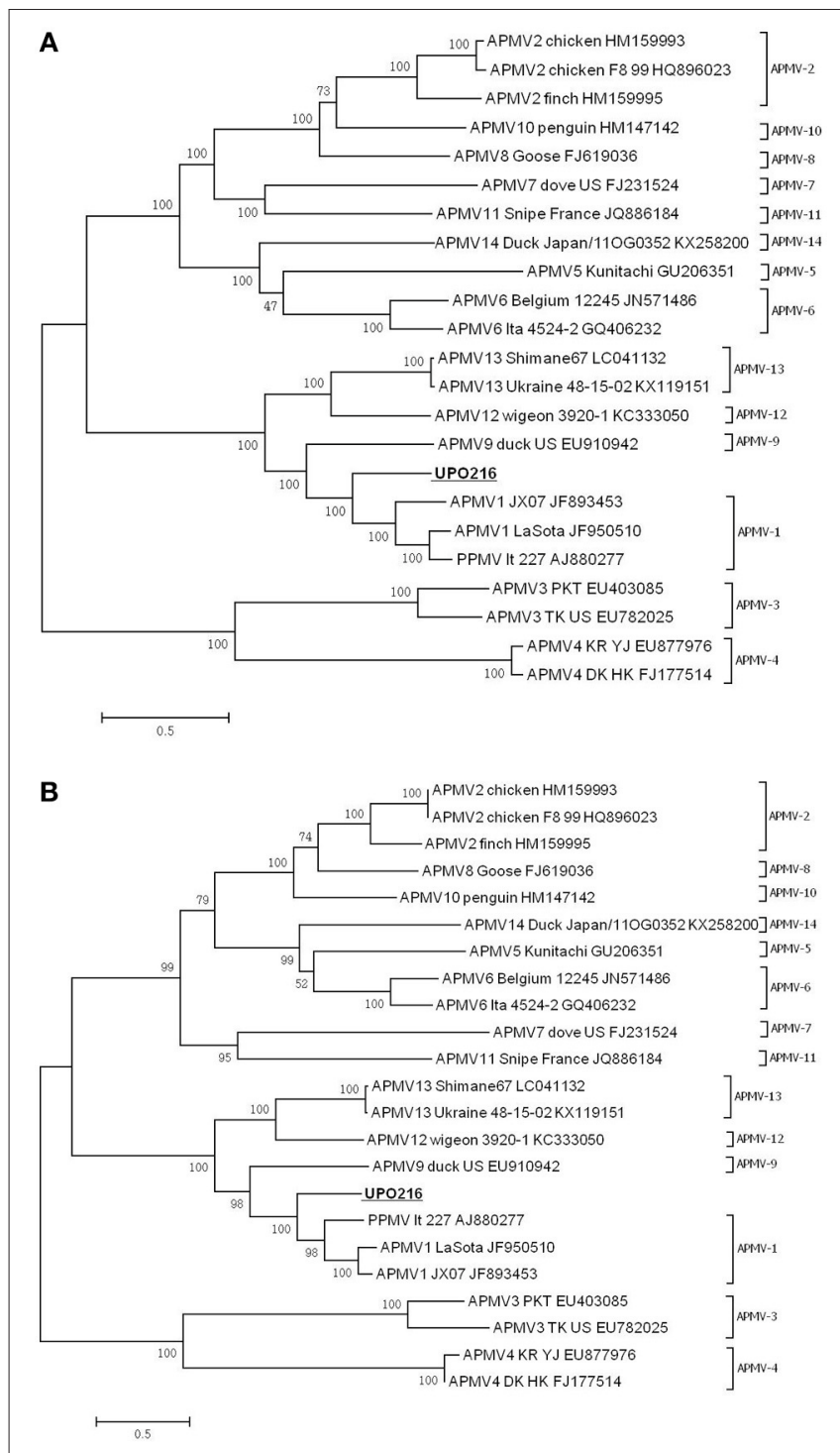

FIGURE 3 | Phylogenetic analysis of the UPO216 virus based on the complete sequence of the genome (A) and F gene (B)

reported in wild birds and penguins around the world (Miller et al., 2010a; Briand et al., 2012; Terregino et al., 2013; Yamamoto et al., 2015; Thampaisarn et al., 2017), implying the presence of additional, as-yet-unreported, novel APMVs in wild birds.

Here, we isolated a hemagglutinating virus (UPO216) from a wild bird fecal sample of unknown species during the 2013/2014 winter season (January 2014) at the UPO wetlands, one of the largest inland wetlands in South Korea. This wetland receives thousands of overwintering migratory birds (mainly ducks and geese) from Arctic regions, starting from late fall. Electron microscopy identified UPO216 as a paramyxovirus, characterized by pleomorphic enveloped virions, projections on the viral envelope, and a "herringbone" nucleocapsid. Fortunately, UPO216 is unlikely to cause clinical disease in chickens since in vivo pathogenicity tests and molecular pathotypic analyses showed that it is avirulent in this species.

Notably, the UPO216 virus in this study has biologically and genetically unique characteristics distinct from known serotypes of APMV reported so far. First, the cross-HI test showed that UPO216 is antigenically distinct from other known serotypes of APMV, although it did cross-react weakly with APMV$1(R=0.088)$ and APMV-9 $(R=0.125)$. Such weak crossreactivity between APMVs is not uncommon (e.g., between APMV-1 and APMV-12 ( $R=0.125)$; Terregino et al., 2013). Second, the genomic features of UPO216 are unique among the 14 APMV serotypes examined (Figure 2). Such features include the sequence and length of the complete genome, the transcriptional units, and the non-translated regions (i.e., GS, GE, intergenic, leader, and trailer sequences). UPO216 also harbors a unique cleavage site within the $\mathrm{F}$ protein (aa sequence LVQAR $\downarrow L$ ), which is distinct from that in known serotypes of APMV. Third, estimates of inter-serotype evolutionary distances based on the nucleotide of the fulllength genome revealed that UPO216 was relative close to APMV-1(0.43), APMV-9(0.64), APMV-12(0.78), and APMV13(0.77), which clustered with UPO216 in phylogenetic analysis. However, the values of the evolutionary divergence were lower than those of the intra-serotypic distances of APMV-1, -2 , -3 , and -6 which genetic diversity within these serotypes has been reported (Alexander, 2003; Miller et al., 2010b; Suarez et al., 2013). Considering the unique characteristics mentioned above, UPO216 appears to be a novel serotype that evolved from a common ancestor and now occupies a separate branch from APMV-1, $-9,-12$, and -13 . Thus, we propose that the UPO216 virus be tentatively classified as a new serotype of APMV (named APMV-15). If this is confirmed to be the case, then the UPO216 virus can be officially named APMV15/WB/Kr/UPO216/2014.

The species of wild birds from which the UPO216 virus was originally isolated was not identified at the time of sampling, since virus isolation was conducted from fresh duck droppings in the UPO wetlands. To identify wild bird species that may act as a natural reservoir for the UPO216 virus, we conducted serological surveillance of a variety of wild birds in Korea, including Anseriformes, Charadriiformes, Ciconiiformes, Columbiformes, and Passeriformes. UPO216-reactive antibodies were detected only in five ducks species (Eurasian teal, European wigeon, mallard, Spot-Billed duck, and mandarin duck) belonging to the Order Anseriformes, although the frequency of sero-positivity in wild ducks was relatively low $(4.0 \%, 20 / 494)$. The majority of UPO216-reactive sera (13/20) from wild ducks (particularly mandarin duck) also reacted with APMV-1 (NDV), which showed $\mathrm{HI}$ titers that were the same or greater than those of UPO216, indicating that sero-positive results could be due to mixed infection with APMV-1 and the UPO216 virus, or to a cross-reaction with APMV-1. UPO216-specific antibodies (i.e., showing no cross-reaction with other APMV serotypes) were detected in serum samples $(n=7)$ from four species: Eurasian teal (1/36), European wigeon (1/73), mallard (4/139), and Spot-Billed duck (1/137). In particular, UPO216-specific antibodies with a $\mathrm{HI}$ titer of $5 \log _{2}$ or greater were detected 
TABLE 5 | Estimated evolutionary divergence between and within APMV groups in terms of complete genome sequences (below diagonal) and HN gene amino acid sequences (above diagonal).

\begin{tabular}{|c|c|c|c|c|c|c|c|c|c|c|c|c|c|c|c|}
\hline APMV serotypes & 1 & 2 & 3 & 4 & 5 & 6 & 7 & 8 & 9 & 10 & 11 & 12 & 13 & 14 & UPO216 \\
\hline 1 & 0.21 & 0.64 & 0.64 & 0.64 & 0.65 & 0.68 & 0.62 & 0.65 & 0.37 & 0.65 & 0.87 & 0.41 & 0.44 & 0.64 & 0.27 \\
\hline 2 & 1.36 & 0.21 & 0.66 & 0.67 & 0.56 & 0.57 & 0.58 & 0.50 & 0.68 & 0.49 & 0.85 & 0.66 & 0.65 & 0.59 & 0.64 \\
\hline 3 & 1.49 & 1.50 & 0.30 & 0.58 & 0.66 & 0.68 & 0.66 & 0.68 & 0.63 & 0.66 & 0.87 & 0.63 & 0.61 & 0.63 & 0.65 \\
\hline 4 & 1.54 & 1.54 & 1.13 & 0.06 & 0.69 & 0.67 & 0.64 & 0.67 & 0.63 & 0.69 & 0.89 & 0.63 & 0.61 & 0.66 & 0.63 \\
\hline 5 & 1.46 & 1.29 & 1.58 & 1.62 & NA & 0.41 & 0.58 & 0.58 & 0.68 & 0.57 & 0.87 & 0.67 & 0.66 & 0.46 & 0.66 \\
\hline 6 & 1.37 & 1.15 & 1.50 & 1.57 & 0.96 & 0.26 & 0.56 & 0.60 & 0.68 & 0.58 & 0.88 & 0.66 & 0.66 & 0.48 & 0.69 \\
\hline 7 & 1.39 & 1.13 & 1.51 & 1.54 & 1.25 & 1.18 & NA & 0.59 & 0.64 & 0.59 & 0.87 & 0.65 & 0.61 & 0.56 & 0.62 \\
\hline 8 & 1.37 & 0.71 & 1.50 & 1.55 & 1.28 & 1.14 & 1.09 & NA & 0.65 & 0.49 & 0.86 & 0.67 & 0.66 & 0.56 & 0.63 \\
\hline 9 & 0.64 & 1.35 & 1.50 & 1.55 & 1.46 & 1.36 & 1.39 & 1.34 & NA & 0.64 & 0.87 & 0.41 & 0.44 & 0.65 & 0.37 \\
\hline 10 & 1.34 & 0.69 & 1.51 & 1.56 & 1.23 & 1.12 & 1.12 & 0.69 & 1.35 & NA & 0.89 & 0.63 & 0.64 & 0.59 & 0.64 \\
\hline 11 & 1.38 & 1.03 & 1.50 & 1.53 & 1.17 & 1.12 & 0.88 & 1.04 & 1.36 & 1.04 & NA & 0.86 & 0.87 & 0.89 & 0.86 \\
\hline 12 & 0.80 & 1.37 & 1.52 & 1.53 & 1.44 & 1.38 & 1.38 & 1.35 & 0.81 & 1.37 & 1.36 & NA & 0.37 & 0.65 & 0.42 \\
\hline 13 & 0.79 & 1.39 & 1.46 & 1.52 & 1.48 & 1.37 & 1.38 & 1.35 & 0.84 & 1.39 & 1.38 & 0.54 & 0.02 & 0.64 & 0.41 \\
\hline 14 & 1.39 & 1.21 & 1.50 & 1.58 & 1.00 & 0.87 & 1.21 & 1.14 & 1.37 & 1.13 & 1.15 & 1.36 & 1.38 & NA & 0.64 \\
\hline UPO216 & 0.43 & 1.36 & 1.53 & 1.55 & 1.49 & 1.37 & 1.36 & 1.35 & 0.64 & 1.37 & 1.36 & 0.78 & 0.77 & 1.35 & NA \\
\hline
\end{tabular}

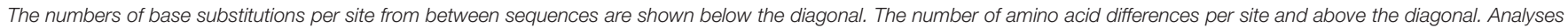
were conducted using the Maximum Composite Likelihood model in MEGA7.0 (Kumar et al., 2016).

Numbers in bold represent the highest divergence based on the complete genome sequences, calculated for different viruses within a group.

NA, not applicable (fewer than 10 sequences were available).

\section{TABLE 6 | Serological tests of UPO216-reactive HI antibodies in serum from wild birds in Korea.}

\begin{tabular}{|c|c|c|c|c|c|c|c|}
\hline Order & Species & No. tested & No. positive (\%) & \multicolumn{4}{|c|}{ HI titer $\left(\log _{2}\right)$} \\
\hline & Anas Penelope (European Wigeon) & 73 & $1(1.4)$ & & $1(1)$ & & \\
\hline & Anas platyrhynchos (Mallard) & 139 & $6(4.3)$ & $1(0)$ & $2(1)$ & $1(1)$ & $2(2)$ \\
\hline & Anas poecilorhyncha (Spot-Billed Duck) & 137 & $3(2.2)$ & $2(0)$ & $1(1)$ & & \\
\hline \multirow[t]{2}{*}{ Charadriiformes } & Larus argentatus (Herring gull) & 4 & 0 & & & & \\
\hline & Larus crassirostris (Black-tailed gull) & 45 & 0 & & & & \\
\hline \multirow[t]{2}{*}{ Ciconiiformes } & Ardea cinerea (Gray heron) & 13 & 0 & & & & \\
\hline & Egretta garzetta (Little egret) & 81 & 0 & & & & \\
\hline \multirow[t]{3}{*}{ Passeriformes } & Cyanopica cyanus (Azure-winged magpie) & 9 & 0 & & & & \\
\hline & Hirundo rustica (Barn swallow) & 4 & 0 & & & & \\
\hline & Passer montanus (Eurasian Tree Sparrow) & 7 & 0 & & & & \\
\hline Total & & 880 & $20(2.3)$ & 9 & 5 & 3 & 3 \\
\hline
\end{tabular}

${ }^{\dagger}$ Numbers in parentheses represent the number of sera showing no cross-reactivity with other serotypes of APMVs.

in mallard ducks. Taken together, these results suggest that at least five species of wild duck (particularly mallard) belonging to the Order Anseriformes might be the natural reservoir for the UPO216 virus in Far Eastern countries, including Korea. Further virus isolation and/or serological surveillance studies in wild ducks, especially migratory birds, are needed if we are to better understand the genetic diversity and ecology of the UPO216 virus. 


\section{AUTHOR CONTRIBUTIONS}

Conceived and designed the experiments: HJL, JK, KC; Performed the experiments: HJL, JK, EL, BS; Supervised and discussed the experiments and data: KC, YL, HSL; Wrote the manuscript: HJL and KC.

\section{REFERENCES}

Alexander, D. J. (2003). Paramyxoviridae. Iowa: Iowa State University Press. Archetti, I., and Horsfall, F. L. Jr. (1951). Persistent antigenic variations of influenza A virus after incomplete neutralization in ovo with heterologous immune serum. Rend. Ist. Sup. Sanit. 14, 909-936.

Briand, F. X., Henry, A., Massin, P., and Jestin, V. (2012). Complete genome sequence of a novel avian paramyxovirus. J. Virol. 86, 7710. doi: 10.1128/JVI.00946-12

Chang, P. C., Hsieh, M. L., Shien, J. H., Graham, D. A., Lee, M. S., and Shieh, H. K. (2001). Complete nucleotide sequence of avian paramyxovirus type 6 isolated from ducks. J. Gen. Virol. 82(Pt 9), 2157-2168. doi: 10.1099/0022-1317-82-9-2157

Choi, K. S., Lee, E. K., Jeon, W. J., Kwon, J. H., Lee, J. H., and Sung, H. W. (2012). Molecular epidemiologic investigation of lentogenic Newcastle disease virus from domestic birds at live bird markets in Korea. Avian Dis. 56, 218-223. doi: 10.1637/9699-030311-ResNote.1

Goraichuk, I., Sharma, P., Stegniy, B., Muzyka, D., Pantin-Jackwood, M. J., Gerilovych, A., et al. (2016). Complete genome sequence of an avian paramyxovirus representative of putative new serotype 13. Genome Announc. 4:e00729-16. doi: 10.1128/genomeA.00729-16

Hall, T. A. (1999). BioEdit: a user-friendly biological sequence alignment editor and analysis program for Windows 95/98/NT. Nucl. Acids. Symp. Ser. 41, 95-98.

Kang, H. M., Jeong, O. M., Kim, M. C., Paek, M. R., Choi, J. G., Lee, E. K., et al. (2010). Surveillance of avian infleunza virus in wild bird fecal samples from South Korea, 2003-2008. J. Wildl. Dis. 46, 878-888. doi: 10.7589/0090-3558-46.3.878

Karamendin, K., Kydyrmanov, A., Seidalina, A., Asanova, S., Sayatov, M., Kasymbekov, E., et al. (2016). Complete genome sequence of a novel avian paramyxovirus (APMV-13) isolated from a wild bird in kazakhstan. Genome Announc. 4. pii: e00167-16. doi: 10.1128/genomeA.00167-16

Kim, S. H., Xiao, S., Shive, H., Collins, P. L., and Samal, S. K. (2012). Replication, neurotropism, and pathogenicity of avian paramyxovirus serotypes 1-9 in chickens and ducks. PLoS ONE 7:e34927. doi: 10.1371/journal.pone.0034927

Kolakofsky, D., Pelet, T., Garcin, D., Hausmann, S., Curran, J., and Roux, L. (1998). Paramyxovirus RNA synthesis and the requirement for hexamer genome length: the rule of six revisited. J. Virol. 72, 891-899.

Kumar, S., Militino Dias, F., Nayak, B., Collins, P. L., and Samal, S. K. (2010). Experimental avian paramyxovirus serotype-3 infection in chickens and turkeys. Vet. Res. 41, 72. doi: 10.1051/vetres/2010042

Kumar, S., Stecher, G., and Tamura, K. (2016). MEGA7: molecular evolutionary genetics analysis version 7.0 for bigger datasets. Mol. Biol. Evol. 33, 1870-1874. doi: 10.1093/molbev/msw054

Lee, Y. J., Kang, H. M., Lee, E. K., Song, B. M., Jeong, J., Kwon, Y. K., et al. (2014). Novel reassortant influenza A(H5N8) viruses, South Korea, 2014. Emerg. Infect. Dis. 20, 1087-1089. doi: 10.3201/eid2006.140233

Li, Z., Yu, M., Zhang, H., Wang, H. Y., and Wang, L. F. (2005). Improved rapid amplification of cDNA ends (RACE) for mapping both the $5^{\prime}$ and $3^{\prime}$ terminal sequences of paramyxovirus genomes. J. Virol. Methods 130, 154-156. doi: 10.1016/j.jviromet.2005.06.022

Miller, P. J., Afonso, C. L., Spackman, E., Scott, M. A., Pedersen, J. C., Senne, D. A., et al. (2010a). Evidence for a new avian paramyxovirus serotype 10 detected

\section{FUNDING}

This research was supported by a grant from the QIA (no. N1543084-2015-99-02), Republic of Korea. The funders played no role in the study design, data collection and analysis, the decision to publish, or preparation of the manuscript.

in rockhopper penguins from the Falkland Islands. J. Virol. 84, 11496-11504. doi: 10.1128/JVI.00822-10

Miller, P. J., Decanini, E. L., and Afonso, C. L. (2010b). Newcastle disease: evolution of genotypes and the related diagnostic challenges. Infect. Genet. Evol. 10, 26-35. doi: 10.1016/j.meegid.2009.09.012

OIE (2012). Available online at: http://www.oie.int/fileadmin/Home/eng/Health_ standards/tahm/2.03.14_NEWCASTLE_DIS.pdf (Accessed).

Reed, L. J., and Muench, L. H. (1938). A simple method of estimating fifty percent endpoints. Am. J. Hyg. 27, 493-497.

Samal, S. K. (2011). Newcastle Disease and Related Avian Paramyxoviruses. Norfolk, UK: Caister Academic Press.

Samuel, A. S., Kumar, S., Madhuri, S., Collins, P. L., and Samal, S. K. (2009). Complete sequence of the genome of avian paramyxovirus type 9 and comparison with other paramyxoviruses. Virus Res. 142, 10-18. doi: 10.1016/j.virusres.2008.12.016

Samuel, A. S., Paldurai, A., Kumar, S., Collins, P. L., and Samal, S. K. (2010). Complete genome sequence of avian paramyxovirus (APMV) serotype 5 completes the analysis of nine APMV serotypes and reveals the longest APMV genome. PLoS ONE 5:e9269. doi: 10.1371/journal.pone.0009269

Steward, M., Vipond, I. B., Millar, N. S., and Emmerson, P. T. (1993). RNA editing in Newcastle disease virus. J. Gen. Virol. 74 (Pt 12), 2539-2547. doi: 10.1099/0022-1317-74-12-2539

Suarez, D. L., Miller, P. J., Koch, G., Mundt, E., Jones, R. C., and Rautenschlein, S. (2013). Newcastle Diseases, Other Avian Paramyxoviruses, and Avian Metapneumovirus Infections. Iowa: John Wiley \& Sons, Inc.

Subbiah, M., Xiao, S., Khattar, S. K., Dias, F. M., Collins, P. L., and Samal, S. K. (2010). Pathogenesis of two strains of avian paramyxovirus serotype 2, Yucaipa and Bangor, in chickens and turkeys. Avian Dis. 54, 1050-1057. doi: 10.1637/9380-041910-Reg.1

Terregino, C., Aldous, E. W., Heidari, A., Fuller, C. M., De Nardi, R., Manvell, R. J., et al. (2013). Antigenic and genetic analyses of isolate APMV/wigeon/Italy/3920-1/2005 indicate that it represents a new avian paramyxovirus (APMV-12). Arch. Virol. 158, 2233-2243. doi: 10.1007/s00705-013-1735-2

Thampaisarn, R., Bui, V. N., Trinh, D. Q., Nagai, M., Mizutani, T., Omatsu, T., et al. (2017). Characterization of avian paramyxovirus serotype 14, a novel serotype, isolated from a duck fecal sample in Japan. Virus Res. 228, 46-57. doi: 10.1016/j.virusres.2016.11.018

Yamamoto, E., Ito, H., Tomioka, Y., and Ito, T. (2015). Characterization of novel avian paramyxovirus strain APMV/Shimane67 isolated from migratory wild geese in Japan. J. Vet. Med. Sci. 77, 1079-1085. doi: 10.1292/jvms.14-0529

Conflict of Interest Statement: The authors declare that the research was conducted in the absence of any commercial or financial relationships that could be construed as a potential conflict of interest.

Copyright (C) 2017 Lee, Kim, Lee, Lee, Song, Lee and Choi. This is an open-access article distributed under the terms of the Creative Commons Attribution License (CC $B Y)$. The use, distribution or reproduction in other forums is permitted, provided the original author(s) or licensor are credited and that the original publication in this journal is cited, in accordance with accepted academic practice. No use, distribution or reproduction is permitted which does not comply with these terms. 